\title{
ОКСЮМОРОН ПО ФОРМЕ И СОДЕРЖАНИЮ: ДИСКУРСИВНЫЕ МЕХАНИЗМЫ ПАССИВНОЙ АГРЕССИИ
}

\author{
А. В. Быстрых, Е. И. Высоцкая
}

Воронежский государственный университет

\section{FORMAL AND CONCEPTUAL OXYMORON: DISCURSIVE MECHANISMS OF PASSIVE-AGGRESSIVE BEHAVIOUR}

\author{
A. V. Bystrykh, E. I. Vysotskaya \\ Voronezh State University
}

\begin{abstract}
Аннотация: предлагаемая статья обращается к проблеме лингвистической трактовки пассивно-агрессивного стиля общения - дискурсивной практики, широко и глубоко проникшей во многие сферы межличностного общения. В качестве изучаемого дискурсивного контекста бытования пассивной агрессии выборается семейный дискурс в силу априори заложенной в нем маркированной властной иерархии коммуникантов и конфронтации между поколениями, а также его ориентации на формирование сообществ практики - неформальных групп коммуникантов, совместно вырабатывающих уникальные нормы дискурсивного поведения в виде обоюдных ожиданий относительно приемлемости того или иного поведения в данной группе. Анализ исследованного корпуса показывает, что пассивная агрессия реализуется за счет реконтекстуализации, как правило, маркировано вежливых форм в ситуацию нарастающего антагонизма между собеседниками. При этом прагматические установки говорящего обнаружсиват противоречие: реализуемые стратегии ликосбережения, нацеленные на учет интересов лица собеседника, вступают в конфликт с установкой на подрыв межличностной гармонии. Независимо от позиции на вертикали власти, пассивный агрессор выступает в роли манипулятора, нацеленного на дестабилизаџию гармонии межличностных отношений. Являясь исключительно контекстно мотивированной формой дискурсивного поведения, пассивно-агрессивный стиль общения не обнаруживает однозначных текстовых и метатекстовых маркеров, что с необходимостью предполагает учет паравербальных характеристик речи.
\end{abstract}

Ключевые слова: пассивная агрессия, невежливость, вежливость, ирония, дискурсивная практика, межличностная гармония, ликосбережение.

\begin{abstract}
: the paper investigates the nature of passive-aggressive behavior which has become ubiquitous in many domains of communication and yet lacks thorough linguistic elaboration. The study draws on the analysis of family discourse which, on the one hand, lends itself well to potential confrontation due to the inherent asymmetrical distribution of power between parents and children, and, on the other hand, is conducive to the emergence of specific communities of practice. Communities of practice are known to define a unique set of expectations for what constitutes polite and impolite behavior. The notion of a community of practice is key to researching firstorder (im)politeness ((im)politeness 1). The study suggests that passive-aggressive illocutions arise when intrinsically polite linguistic forms are recontextualised into a socially opposite context. Like its oxymoronic name, the intent of the passive-aggressive speaker is a contradiction in terms: his explicit face-saving strategies clash with a pronounced rapport-challenging orientation. In fact, the obtained evidence demonstrates that the relative power of the passive-aggressive speaker does not seem to account for the chosen communication style which comes down to a sophisticated form of manipulation. Passive-aggressive linguistic forms are arguably contextsensitive and can only be adequately interpreted in conjunction with the accompanying paralinguistic cues.
\end{abstract} Key words: passive-aggressive, impoliteness, politeness, irony, discursive practice, rapport, face saving.

(С) Быстрых А. В., Высоцкая Е. И., 2020

Контент доступен под лицензией Creative Commons Attribution 4.0 License. The content is available under Creative Commons Attribution 4.0 License. 


\section{Введение}

В последнее время пассивная агрессия как название достаточно широкого спектра поведенческих практик коммуникантов становится крайне востребованным клише в области теории коммуникации. Наивно-бытовое преломление этот термин получает в интернет-пространстве, которое пестрит такими заголовками, как «7 правил общения с пассивноагрессивным человеком», «Как бороться с пассивноагрессивным поведением», «Как проявляется пассивная агрессия», «10 фраз, которые произносит пассивный агрессор» и т. д. Вместе с тем, относясь к домену межличностной коммуникации, до настоящего момента данное поведенческое клише не получило какой-либо четкой лингвистической трактовки, прежде всего в рамках коммуникативно-дискурсивной парадигмы описания естественной коммуникации.

Настоящее исследование является попыткой определить дискурсивную природу пассивно-агрессивного стиля общения (далее ПАСО), выявить механизмы его реализации в семейном дискурсе, а также определить границы данной коммуникативной практики на фоне прагматически смежных феноменов, традиционно относимых к так называемой игривой невежливости (playful impoliteness). Отталкиваясь от постулатов совершившей за последние два десятилетия «дискурсивный поворот» теории вежливости [1-3], мы также ответим на следующие вопросы: 1) насколько возможно говорить об обусловленности ПАСО особой конфигурацией контекстно-ситуационных параметров (прежде всего, распределением власти); 2) в чем состоит глобальная коммуникативная цель пассивного агрессора, и за счет каких тактик она достигается; 3) можно ли выделить вербальные маркеры ПАСО.

\section{Пассивно-агрессивный стиль общения как объект лингвистического анализа}

Одной из причин того, почему пассивно-агрессивные иллокуции до сих пор не стали предметом пристального внимания лингвистов, является терминологическая и понятийная размытость такого широкого коммуникативно-прагматического континуума, как имплицируемая невежливость (implicational impoliteness). Представляется, что данный термин является зонтичным для объединения широкого круга коммуникативных практик, при которых, согласно Дж. Калпеперу, «коммуниканты интерпретируют то, что было сказано (или сделано) или не сказано (или сделано) в определенном контексте как невежливое, несмотря на тот факт, что то, что было сказано (или сделано), не было преподнесено в виде невежливости (pre-loaded for impoliteness)» [4, p. 435]. При этом автор подчеркивает, что ключевым механизмом акту- ализации такого рода иллокуций является рассогласование (mismatch) текстовых и контекстных параметров, выливающееся в значительную степень парадоксальности транслируемого сообщения.

Отметим, однако, что нарушение прагматической целостности пассивно-агрессивных иллокуций не является серьезной препоной для адресата при исчислении передаваемых оттенков невежливости, в том числе потому, что этикетные речевые формулы крайне гибки и часто подвергаются реконтекстуализации - помещению в прагматически альтернативный контекст, в связи с чем, согласно Б. Фрейзеру и У. Нолену, интерактанты в первую очередь оценивают контекст использования тех или иных речевых оборотов, а не сами обороты [5]. Именно поэтому даже самые вежливые по форме клише, типа «Thank you», «Have a nice day», «Fine» и т. д., произнесенные в определенных обстоятельствах с определенными установками, могут восприниматься как невежливые. Заметим при этом, что контекстные и интратекстовые (co-textual) рассогласования, характерные для имплицируемой невежливости [6, p. 465], зачастую характеризуются мультимодальностью (multimodularity), так как адресанту приходится оценивать всю совокупность динамически взаимодействующих сигналов: текстовых, контекстных, фонационных, кинетических и т. д. В конечном итоге именно сложные и противоречивые конфигурации вербальных и невербальных стимулов предопределяют крайне непростую дискурсивную природу пассивной агрессии.

Возвращаясь к терминологической неоднородности, относящейся к тому кругу дискурсивных практик, которые можно квалифицировать как пассивную агрессию, отметим, что ряд исследователей [6-8] предпочитают использовать термин притворная вежливость (mock politeness), акцентируя внимание на ироничном (игривом) характере таких иллокуций. $\mathrm{C}$ точки зрения традиционной прагматики, притворство имеет своей целью сокрытие фактически актуализируемых условий успешности высказывания, что является источником порождения импликатур, прежде всего конверсационных [9]. В случае пассивной агрессии целесообразно говорить об особом типе импликатур - импликатурах невежливости, исчисляемых адресатами за счет использования механизмов инференции при дешифрации таких высказываний. Как известно, глагол «иронизировать» не может выстраивать перформативную рамку высказывания («иллокутивное самоубийство», по 3. Вендлеру [10]) в силу наличия в его значении специфичного смысла «сокрытие истинного коммуникативного намерения». Иронизировать в интересующем нас контексте значит играть комедию, симулировать, притворяться. Именно поэтому лингвисты, отдающие предпочтение термину притворная вежливость в противополож- 
ность термину имплицируемая невежливость, подчеркивают игривый характер таких дискурсивных практик, смещая акцент на то, что симулирующий коммуникант опирается при речепорождении на закрепившиеся конвенции вежливости.

Дж. Лич, рассуждая о природе косвенности в невежливых иллокуциях, использует термины сарказм и конверсаџионная ирония. Они направлены на скрытое нанесение ущерба социальному лицу адресата. При этом подчеркивается, что сарказм и конверсационная ирония выступают не только в роли атакующих стратегий, но и оставляют за говорящим возможность «обороняться» за счет «отнекивания» - уверения собеседника в случае эскалации конфронтации, что имплицитный смысл не закладывался в его интенцию [7, р. 236].

Указанные дискурсивные практики, несомненно, обнаруживают много сходств с пассивно-агрессивным стилем общения. Тем не менее далеко не все саркастические комментарии или ироничные замечания в адрес собеседника, по нашему мнению, могут быть квалифицированы как случаи реализации ПАСО. Далее мы попытаемся определить уникальные для ПАСО дискурсивные механизмы реализации, отталкиваясь от постулатов дискурсивной теории (не)вежливости («(не)вежливость 1») [1-3]. Не имея возможности детально останавливаться на ключевых положениях этой концепции, отметим лишь то, что данная теория отрицает построение универсальных моделей (вежливого или невежливого) поведения в связи с тем, что оценка того или иного эпизода общения в терминах вежливо/невежливо остается исключительно за непосредственными участниками общения и производится ими на основе гибкого, не обязательно рационального и недоступного третьим лицам анализа разворачивающейся интеракции. Наряду с этим данная оценка вежливости является дискурсивно вырабатываемой (mutually negotiable), носит эмергентный характер и не закрепляется в качестве нормы. Принципиальным моментом при этом является смещение фокуса на «фактор адресата». Перефразируя знаменитую английскую пословицу «Красота заключена в глазах наблюдателя» («Beauty is in the eye of the beholder»), Дж. Калпепер утверждает, что «(не)вежливость заключена в глазах и ушах наблюдателя» [11, p. 392]. Такой ракурс на проблему невежливости (приравниваемой в теории «невежливости 1» к дискурсивной неуместности) тех или иных высказываний заставляет Дж. Калпепера несколько девальвировать роль интенции говорящего и, наоборот, акцентировать субъективную оценку адресата: «Невежливость порождается тогда, когда (1) говорящий намеренно наносит урон лицу собеседника, либо (2) слушающий воспринимает и/или конструирует поведение как намеренно угрожающее его лицу, либо в случае сочетания (1) и (2)» [там же].

\section{Материалы и методы исследования}

Материалом для исследования послужили более 100 контекстов, извлеченных методом целевой выборки из британского ситуационного сериала «Му Family» (7 сезонов по 9-14 серий в каждом, длительностью 26-28 минут), который с 2000 г. транслировался на канале ВBC One в течение 11 лет. Выбор данного источника эмпирических данных обусловлен несколькими причинами. Во-первых, ситуационная комедия (sitcom) как особый телевизионный жанр наиболее точно отражает естественную речь героев, помещая их в контекст быта и повседневности. Во-вторых, поскольку целью нашего исследования являлся анализ пассивно-агрессивных иллокуций, по определению встречающихся в условиях, по крайней мере, умеренного антагонизма между собеседниками, было важно отобрать материал, который бы уже на входе указывал на повышенный уровень межличностной конфронтации. На первичных этапах сбора материала мы пришли к выводу, что именно семейный дискурс является наиболее благодатной почвой для анализа ПАСО в силу того, что члены семьи, взаимодействуя друг с другом, формируют так называемое сообщество практики (community of practice). Данный термин сегодня широко используется в дискурс-анализе для описания сообществ коммуникантов, которые вырабатывают свой собственный стиль общения через взаимное, не всегда рациональное, осмысление того, что является приемлемым и неприемлемым в общении друг с другом. При этом внешние (прескриптивные) нормы и оценки не имеют довлеющего значения [12, p. 3]. Отсюда следует, что в семье как особой разновидности сообщества практики формируются свои собственные пределы допустимости в отношении используемых дискурсивных практик, в том числе в отношении имплицируемой невежливости. Данные поведенческие модели становятся частью интериоризованного опыта членов данного сообщества (габитуса (habitus)) [1, p. 155]), являющегося главным мерилом «благоразумного» (politic) поведения. Наконец, еще одной причиной выбора семейного дискурса в качестве источника корпусного материала была попытка проследить значимость контекстных факторов на порождение невежливости. Еще на заре прагмалингвистических исследований вежливости П. Браун и С. Левинсоном в качестве аксимомы была преподнесена обусловленность выбора ликосберегающих стратегий такими социопрагматическими факторами, как социально-психологическая дистанция между собеседниками (distance), относительная власть (приоритетность) одного коммуниканта над другим (power) и степень вмешательства действия в личные и социальные интересы собеседника (rank of imposition) [13, p. 74]. Поскольку семейный дискурс характеризуется неравной дистри- 
буцией властных полномочий между родителями и детьми, с одной стороны, и относительно паритетным властным статусом супругов - с другой, отобранный корпусный материал позволил нам, в том числе, отследить влияние данной социо-прагматической переменной на реализацию невежливых иллокуций.

Как уже было отмечено, корпусный материал отбирался методом целевой выборки, при этом поскольку имплицируемая невежливость имеет крайне эфемерный характер, вслед за [14] идентификация эпизодов ПАСО проводилась в опоре на доступные нашему восприятию просодические и кинетические сигналы невежливости, сопровождающие иллокуции участников и реакции на них.

\section{Результаты исследования}

Анализ собранного материала убедительно демонстрирует то, что пассивная агрессия характеризуется особой конфигурацией прагматического значения, как правило, не ограничивающейся рассогласованием интратекстовых или тексто-контекстных параметров, характерным для имплицируемой невежливости. Принципиальным отличием ПАСО является двунаправленность стратегических установок коммуниканта: реализуемые стратегии ликосбережения, учитывающие интересы лица собеседника, вступают в конфликт с установкой на подрыв межличностной гармонии. Иными словами, коммуникант, придерживающийся пассивно-агрессивного стиля общения, ведет двойную игру: пытаясь угодить собеседнику здесь и сейчас с точки зрения сохранения его права на свободу и автономию (негативное лицо) и/или уважение (позитивное лицо), он ставит под удар гармонию межличностных отношений, не ограничивающуюся актуальным эпизодом общения и не замыкающуюся на соблюдении интересов лица собеседника. Такая реконтекстуализация формально и содержательно вежливых высказываний в «социально противоположный» контекст - ситуацию антагонизма (конфронтации) - порождает пассивно-агрессивные иллокуции.

Продемонстрируем это на следующем примере.

Жена (А) и муж (B) обсуждают, чем заняться на выходных.

A: So what are we going to do? Clear out the garage? Fix that dodgy window? We should be having fun.

B: Lead me to it, Susan.

A: Well, I've made a mental list. We could go looking for antiques, shopping for organic vegetables and finish with Tate Modern.

B: Yup, yup, yup. That's That is a mental list.

A: What's wrong with Tate Modern?

B: You take tours there. But that's work.

A: This is fun.
B: Believe me, for me, it's work.

A: All right. Let's stay here and put photos in the album.

B: Oh, that's great! Oh, yes! Oh, I'm sick with excitement. More fun than a sailor's birthday. On a scale of fun to ten, that's fun, fun.

A: All right, all right. I take your point.

[My family, Season 5, 26.39-27.04]

Совершенно очевидно, что муж в данном эпизоде пытается эквилибрировать между нежеланием обидеть супругу и стремлением отстоять свои интересы. Реализуя тактику подчеркнутого согласия (одобрения), сопровождаемую нетипичной для РА согласия просодией, он подрывает гармонию межличностных отношений с супругой за счет контраста между реализуемой стратегией позитивной вежливости и незаинтересованностью в солидаризации их интересов. Как уже отмечалось, такая стратегическая линия поведения оставляет за говорящим возможность «отменить» транслируемые конфронтационные иллокуции, если пассивная агрессия спровоцирует эскалацию конфликта. При этом важно, что несмотря на ироничный характер согласия (за счет нарушения Принципа кооперации и условий успешности PA согласия), в данном случае стратегически выбранная форма реализации данного акта не представляет никакой угрозы именно интересам лица собеседника, что принципиально отличает такую дискурсивную практику от смежных форм имплицируемой невежливости, например сарказма, который, согласно словарю Merriam Webster, является способом сатирического остроумия с использованием злостного, едкого и часто ироничного языка, направленного против лица человека [15].

Отчасти такой ракурс на проблему выявления дискурсивных механизмов реализации имплицируемой невежливости созвучен с теорией управления межличностной гармонией (rapport management), предложенной X. Спенсер-Оути в качестве альтернативы традиционным моделям вежливости, абсолютизирующим ликосбережение как основу вежливой коммуникации [16]. Теоретик убедительно показывает, что гармонизация коммуникации не ограничивается учетом интересов социальных лиц обоих коммуникантов (что наиболее актуально для западных культур), но и должна с необходимостью учитывать другие, менее доступные для теоретического моделирования факторы - взаимные ожидания коммуникантов относительно поведения друг друга, формирующиеся в привязке к определенным социальным контекстам (sociality rights and obligations) и интеракциональные цели коммуникантов (interactional goals), которые могут быть ориентированы как на цели собеседника (relational), так и на конечный результат коммуникации (transactional). X. Спенсер-Оути под- 
черкивает, что гармония межличностных отношений в различных культурах и эпизодах общения зависит от того, какому фактору определенная культура или участники определенного дискурсивного события придают большую значимость, при этом другие факторы могут либо игнорироваться, либо подчиняться приоритетному.

Представляется, что в случае ПАСО конечной целью коммуниканта является именно зондирующая дестабилизация межличностной гармонии: говорящий не решается на эскалацию конфликта, тем не менее стратегически выстраивает свое поведение таким образом, чтобы создать предпосылки потенциальной конфронтации при максимально возможном сохранении того позитивного образа собеседника, который тот хочет иметь в глазах других здесь и сейчас.

Проведенный анализ показывает, что в семейном дискурсе пассивно-агрессивные иллокуции чаще всего камуфлируются следующими речевыми актами: РА согласия, РА одобрения, РА согласия выполнить действие, РА разрешения, РА благодарности, РА похвалы/комплимента. Как видим, данные речевые акты являются прагматически разнородными, однако их объединяет то, что отказ от выполнения данных действий (withdrawal) будет гораздо более разрушителен для гармонии межличностных отношений по сравнению с реализацией их ироничных вариантов. В самом деле, отсутствие благодарности за услугу или молчание в ответ на просьбу рассматривается как нарушение базовых принципов общения и приводит к гораздо большему антагонизму между коммуникантами, чем в случае ПАСО.

Девушка (А) просит одногруппницу (B) закончить эссе как можно скорее.

A: Sarah, could you just finish it till Monday?

B: Well, I'm not sure, but I'll do my best.

A: Thanks. Take your time.

[My family, Season 5, 21.11-21.16]

В данном контексте РА притворной благодарности выступает как типичное средство передачи ПАСО, причем ироничный настрой коммуниканта передается не только просодически, но и за счет употребления директива Take your time, идущего вразрез с предыдущей просьбой говорящего закончить написание эссе как можно скорее. Очевидно, что пассивная агрессия в виде фиктивной благодарности в данном случае - «меньшее зло», чем маркированное молчание $^{1}$ в ответ на обещание, в выполнение которого говорящий не верит.

${ }^{1}$ Мы отдаем себе отчет в том, что молчание как реакция на инициативную реплику собеседника в определенных условиях также может быть квалифицирована как крайняя форма пассивной агрессии. Однако умышленное уклонение от совершения дискурсивно ожидаемого коммуникативного хода (withdrawal) требует особой методологии анализа и в определенной степени «вживания» лингвиста-аналитика в роль жертвы пассивной агрессии.
Следующей задачей нашего исследования было отслеживание потенциально возможных корреляций между избираемым пассивно-агрессивным стилем общения и социо-прагматическими параметрами контекста, прежде всего властью как вертикальной дистанцией между коммуникантами в статусной иерархии. Как известно, социально-экономическая власть, как правило, проецируется в коммуникативную власть, которая рассматривается как прерогативное право одного из коммуникантов (коммуникативного лидера) «на осуществление определенных речевых действий, на употребление того или иного типа языковых единиц, на определенный тип коммуникативного поведения, а также право распоряжаться коммуникативными действиями партнера по общению» $[17$, с. 3$]$.

Долгое время в качестве аксиомы в теории вежливости бытовало утверждение П. Браун и С. Левинсона о том, что коммуникативное поведение более властного коммуниканта характеризуется меньшей вежливостью (и в том числе меньшей косвенностью). Несмотря на то, что сегодня данный тезис отнюдь не воспринимается как универсальная истина, нам было любопытно посмотреть, насколько он правомерен в отношении ПАСО с его сложной конфигурацией прагматических установок.

Особенно показательным для данных целей был анализ эпизодов общения родителя и ребенка - интерактантов, априори наделенных разными властными полномочиями в условиях протекания общения на близкой социально-психологической дистанции. Заметим тем не менее, что близость горизонтальной дистанции в рассматриваемом ситкоме никоим образом не нивелирует достаточно большую вертикальную дистанцию, так как его сюжет строится на теме непреодолимого конфликта поколений. Проведенный анализ показал, что в семейном дискурсе не наблюдается линейной корелляции между властным статусом коммуниканта и выбором в пользу ПАСО. Данный дискурсивный стиль относительно равномерно встречается как в речи детей, так и в речи родителей при общении друг с другом. Между тем пассивная агрессия как завуалированный инструмент подрыва межличностной гармонии используется представителями разных поколений в разных целях.

В случае если к ПАСО прибегает собеседник с более низким властным статусом (ребенок), как правило, с его стороны коммуникация выстраивается в направлении подрыва сложившегося «статуса кво» и оспаривания авторитета/господства родителя. Типичное для ПАСО внешнее удовлетворение интересов лица собеседника является в этом случае ни чем иным, как скрытым манипулятивным механизмом, направленным на «раскачивание лодки». Это своего рода зондирующая, поэтапная дестабилизация того типа межличностных отношений, который не устра- 
ивает пассивного агрессора. Так, в следующем примере мы наблюдаем типичный сценарий пассивноагрессивного поведения со стороны ребенка, который ради того, чтобы удовлетворить сиюминутные интересы позитивного лица родителя, соглашается следовать полученным наставлениям, но показывает при этом характерной просодией крайнее равнодушие и отвлеченность.

Мать (А) просит дочь не устраивать шумные ночные вечеринки.

A: Hi, Janey! Your life sounds so fun up there I just love hearing all your late night parties. They're great, but listen some people need to sleep and then go to work in the morning. So I just want to let you know but keep having fun, great late night party.

\section{B: No problem, bye.}

[My family, Season 3, 12.11-12.33]

В случае если роль пассивного агрессора принимает на себя родитель при общении с ребенком, то характерная для данной дискурсивной практики реконтекстуализация вежливых иллокуций в контекст социального противостояния служит средством укрепления властных полномочий коммуниканта. При этом манипулятивный характер ПАСО прослеживается и в этом случае: иронично угождая статусно зависимому собеседнику через реализацию «желательных» для него иллокуций, говорящий играет «в поддавки», усиливая при этом конфронтацию через демонстрацию неуязвимости своей позиции и зависимого статуса собеседника. Ср. следующий контекст, в котором родитель последовательно укрепляет статус коммуникативного и социального лидера (авторитета), играя на уязвимости позиции ребенка.

Мать (А) не позволяет сыну (В) оставить дома кролика, купленного им в зоомагазине.

A: Hello. What is that?

B: It's a rabbit.

A: I can see it's a rabbit but what is it?

B: Well, I wanted a rabbit so I bought a rabbit.

A: You didn't ask our permission.

B: Well, I'm rebelling.

$\mathrm{A}:$ A rebel with a rabbit.

B: It's a symbol of my independence.

A: That's nice, dear. Take it back to the shop.

B: If you make me take it back, I'll never believe you again. I'll become aimless and remote, my schoolwork will suffer.

A: Welcome to your new home.

[My family, Season 7, 1.31-2.05]

Таким образом, в случае реализации пассивной агрессии, в отличие от контекстов прототипической (не контекстно мотивированной) невежливости, представляется невозможным говорить о ее обусловленности властным статусом коммуниканта. В усло- виях асимметрии властных отношений между членами семьи пассивную агрессию отличает дискурсивная гибкость, так как она может быть обоюдно манипулятивно использована коммуникантами, находящимися на разных полюсах семейной иерархии.

Универсальной характеристикой пассивных агрессоров в контексте семейного дискурса, по-видимому, является использование особого манипулятивного режима речевого воздействия на собеседника, который мы условно называем «игра в поддавки». Во всех выявленных контекстах реализации ПАСО говорящий идет на открытые уступки собеседнику (реализуя стратегии ликосбережения), но при этом наносит удар по ключевой для него цели - балансу межличностных отношений. Более того, как правило, реализуемые стратегии ликосбережения характеризуются использованием маркированных речевых форм, конвенционализованных в качестве вербальных сигналов вежливости в соответствующих речевых событиях. Ср. уже приводимую нами тактику подчеркнутого согласия (одобрения), а также тактику подчеркнутой готовности совершить действие (PA обещания, РА предложения услуги, РА согласия выполнить просьбу) и тактику демонстративного дистанцирования (директивные РА) в следующих контекстах:

Жена (А), не считая, что она должна мыть посуду, «изъявляет желание» сделать это вместо мужа (В).

A: Would you hand me those plates? do

B: Not now. I've got to go and find something else to

A: Oh, fine, don't worry about cleaning the table. I can do it. After I've folded the clothes, descaled the kettle-and hoovered your crumbs off the sofa.

[My family, Season 2, 16.45-16.58]

Сын (А) напоминает отцу (В) о том, что он должен прочесть его эссе.

A: Do you want to read it?

B: Sure. Yeah. Just leave it on the coffee table.

A: It's been on the coffee table for three weeks.

[My family, Season 4, 22.21-22.33]

Родитель (А) в очередной раз напоминает ребенку

(В) вынести мусор.

A: Did you ever take out the trash?

B: Oh no, I'll do it right now.

A: It's okay. I'll take care of it.

[My family, Season 1, 17.17-17.21]

Мать (А) не разрешает дочери (В) красить ногти за обеденным столом.

A: I've told you about painting nails at the table.

B: I wasn't listening.

A: Do whatever you want.

[My family, Season 1, 10.15-10.20] 
Как видим, в данных эпизодах происходит прагматическое переосмысление речевых форм (в том числе этикетных), конвенционально употребляемых в англоязычных культурах как маркеров вежливости. Симулирующий коммуникант эксплуатирует достаточно жестко закрепившуюся ассоциативную связь между речевой формой и вежливой моделью поведения, помещает эти формы в контекст социального противостояния и тем самым порождает пассивную агрессию per se. Безусловно, привязка таких форм к вежливым дискурсивным практикам крайне сильна, и для их реализации в качестве сигналов ПАСО решающее значение будет иметь соответствующий прагматический контекст вкупе с соответствующими просодическими и кинетическими характеристиками речи (тон нетерпения, ухмылка и т. д.). По этой причине представляется несколько поспешным выделение собственно вербальных (текстовых и метатекстовых) маркеров пассивно-агрессивного дискурсивного общения, что как раз соответствует общему лейтмотиву постмодернистской теории (не) вежливости, декларирующей невозможность конструирования универсальной теоретической модели (не)вежливого поведения (см. выше). Еще более спорным выглядит уравнивание маркеров невежливости с прагматическими маркерами дискурса, как, например, это делается в работе [18]. Прагматикализация значения всегда предполагает изменение категориального статуса семантики соответствующей речевой (или языковой) единицы, в том числе в связи с функциональным сдвигом: пропозициональные смыслы замещаются меж- или надпропозициональными. В случае пассивной агрессии (как и в большинстве других типов невежливости) не наблюдается функционального сдвига, так как априори вежливая речевая формула всего лишь предстает в другой («социально противоположной») ипостаси за счет помещения в альтернативный дискурсивный контекст.

Между тем приведенные размышления относительно объективной сложности определения текстовых и метатекстовых маркеров пассивной агрессии требуют одной оговорки. Анализ пассивно-агрессивного общения в семейном дискурсе показывает, что отдельные формально вежливые речевые формы могут «обрастать» шлейфом пассивно-агрессивных коннотаций и в коллективной памяти отдельного сообщества практики (габитусе) фиксироваться как невежливые без привязки к дискурсивному контексту. Особенно показательным в этом отношении в исследованном корпусе является пассивно-агрессивное употребление автономных слов-вставок fine и thanks (в противоположность thank you, thanks a lot и т. д.). По нашим наблюдениям, данные формы, употребляясь в дискурсивно непрозрачном контексте, могут негативно восприниматься адресатом. Одной из причин такого восприятия этих форм может быть то, что на протяжении совместной дискурсивной деятельности у членов определенного сообщества практики вырабатываются взаимные ожидания, руководствуясь которыми участники сообщества квалифицируют речевые формы и стоящие за ними действия как вежливые или невежливые (cp. понятие о вежливости как конверсационном контракте [5]). Иными словами, в их понимании быть вежливым значит придерживаться совместно сконструированных дискурсивных норм. Если определенная речевая форма (или действие) по какой-то причине компрометирует себя как невежливая в глазах участников сообщества, то и в дальнейшем она будет негативно ими оцениваться безотносительно контекста. Это особенно справедливо в отношении так называемых недостаточно вежливых форм (ср. понятие underpoliteness у Дж. Лича [7]), механическое использование которых зачастую порождает иллокуции невежливости.

\section{Заключение}

Проведенное исследование позволяет рассмотреть пассивную агрессию как особую дискурсивную практику, заключающуюся в реконтекстуализации формально и содержательно вежливых высказываний в социально противоположный контекст - ситуацию антагонизма (конфронтации). При этом стратегическая линия поведения коммуниканта является двунаправленной: реализуемые стратегии ликосбережения, нацеленные на учет интересов лица собеседника, вступают в конфликт с установкой на подрыв межличностной гармонии.

В семейном дискурсе симулирующий коммуникант выступает как манипулятор, дискурсивные маневры которого условно можно назвать «игрой в поддавки». Используемые им уступки выражаются в эксплуатации маркированных тактик вежливого поведения. При этом решающее значение для интерпретации реализуемых иллокуций как невежливых имеют сопутствующие просодические и кинетические характеристики речи говорящего, что с необходимостью предполагает рассмотрение пассивной агрессии как мультимодальной дискурсивной практики.

Проведенный анализ семейного дискурса не демонстрирует обусловленность ПАСО властным статусом коммуниканта. В роли пассивного агрессора может выступать и коммуникативный лидер, и властно зависимый собеседник. Первый, как правило, старается укрепить свои властные полномочия, второй - подорвать авторитет первого.

Учитывая, что пассивная агрессия является исключительно контекстно связанной формой дискур- 
сивного поведения, представляется невозможным говорить о выделении текстовых и метатекстовых маркеров ПАСО. Тем не менее наибольший пассивно-агрессивный потенциал проявляется у конвенционализованных формул вежливости, реконтекстуализация которых создает эффект прагматического парадокса.

\section{ЛИТЕРАТУРА}

1. Watts R. J. Politeness. New York : Cambridge University Press, 2003. 306 p.

2. Locher $M$. Power and politeness in action : Disagreements in Oral Communication. Mouton de Gruyter, Berlin, 2004. 365 p.

3. Mills $S$. Gender and politeness. Cambridge : Cambridge University Press, 2003. 256 p.

4. Culpeper J. Impoliteness strategies // Interdisciplinary Studies in Pragmatics, Culture and Society. Cham : Springer International Publishing, 2016. Pp. 421-443.

5. Fraser B., Nolen $W$. The Association of deference with linguistic form // International Journal of the Sociology of Language. 1981. № 27. Pp. 93-109.

6. Taylor Ch. Mock politeness and culture : Perceptions and practice in UK and Italian data // Intercultural Pragmatics. 2016. № 13 (4). Mouton de Gruyter. Pp. 463-498.

7. Leech $G$. The pragmatics of politeness. New York : Oxford University Press, 2014. 350 p.

8. De Marlangeon K., Alba-Juez S. \& L. A typology of verbal impoliteness behavior for the English and Spanish cultures // Revista Española de Lingüística Aplicada. 2012. № 25. Pp. 69-92.

9. Grice H. P. Logic and conversation // Syntax and Semantics : Speech Acts. New York : Academic, 1975. Pp. 41-58.

10. Vendler Z. Linguistics in philosophy. Ithaca, N. Y. : Cornell Univ. Press, 1967. 203 p.

11. Culpeper J. Politeness and Impoliteness // Handbook of pragmatics. 2011. Vol. 5. Pp. 391-436.

12. Jaworski A., Coupland N., Galasinski D. Metalanguage: why now? // Metalanguage : Social and Ideological Perspectives. Berlin : Mouton de Gruyter. 2004. Pp. 3-10.

13. Brown P., Levinson $S$. Universals in language usage : Politeness phenomena // Questions and politeness : Strategies in social interaction. Cambridge : Cambridge University Press, 1978. Pp. 56-311.

14. Culpeper $J$. «It's not what you said, It's how you said it!» : Prosody and impoliteness // Discursive Approaches to Politeness. Berlin ; Boston : de Gruyter Mouton, 2011. Pp. 57-83.

15. URL: https://www.merriam-webster.com/dictionary/sarcasm

16. Spencer-Oatey $H$. Introduction : language, culture and rapport management // Culturally Speaking : Culture, Communication and Politeness Theory. 2008. Pp. 1-10.

17. Черватюк И. С. Власть как коммуникативная категория : автореф. дис. ... канд. филол. наук. Волгоград, 2006. $24 \mathrm{c}$.
18. Alba-Juez L. On the impoliteness of some politeness strategies : a study and comparison of some pragmatic markers of impoliteness in British English and American English, Peninsular Spanish and Argentine Spanish // Studies in Intercultural, Cognitive and Social Pragmatics. Cambridge Scholar Publishing, 2007. Pp. 37-56.

\section{REFERENCES}

1. Watts R. J. Politeness. New York: Cambridge University Press, 2003.

2. Locher M. Power and politeness in action: Disagreements in Oral Communication. Mouton de Gruyter, Berlin, 2004.

3. Mills S. Gender and politeness. Cambridge: Cambridge University Press, 2003.

4. Culpeper J. Impoliteness strategies. In: Interdisciplinary Studies in Pragmatics, Culture and Society. Cham: Springer International Publishing, 2016. Pp. 421-443.

5. Fraser B., Nolen W. The Association of deference with linguistic form. In: International Journal of the Sociology of Language. 1981. No. 27. Pp. 93-109.

6. Taylor Ch. Mock politeness and culture: Perceptions and practice in UK and Italian data. In: Intercultural Pragmatics. Mouton de Gruyter. 2016. No. 13 (4). Pp. 463-498.

7. Leech G. The pragmatics of politeness. New York: Oxford University Press, 2014.

8. De Marlangeon K., Alba-Juez S. \& L. A typology of verbal impoliteness behavior for the English and Spanish cultures. In: Revista Española de Lingüística Aplicada. 2012. No. 25. Pp. 69-92.

9. Grice H. P. Logic and conversation. In: Syntax and Semantics: Speech Acts. New York: Academic, 1975. Pp. 41-58.

10. Vendler Z. Linguistics in philosophy. Ithaca, N. Y.: Cornell Univ. Press, 1967.

11. Culpeper J. Politeness and Impoliteness. In: Handbook of pragmatics. 2011. No. 5. Pp. 391-436.

12. Jaworski A. et al. Metalanguage: why now? In: Metalanguage: Social and Ideological Perspectives. Berlin: Mouton de Gruyter, 2004. Pp. 3-10.

13. Brown P., Levinson S. Universals in language usage: Politeness phenomena. In: Questions and politeness: Strategies in social interaction. Cambridge: Cambridge University Press, 1978. Pp. 56-311.

14. Culpeper J. «It's not what you said, It's how you said it!»: Prosody and impoliteness. In: Discursive Approaches to Politeness. Berlin; Boston: de Gruyter Mouton, 2011. Pp. 57-83.

15. Available at: https://www.merriam-webster.com/ dictionary/sarcasm

16. Spencer-Oatey H. Introduction: language, culture and rapport management. In: Culturally Speaking: Culture, Communication and Politeness Theory. 2008. Pp. 1-10.

17. Chervatiuk I. S. Vlast kak kommunikativnaia kategoriia [Power as communicative category]. PhD Thesis Abstract. Volgograd, 2006. 
18. Alba-Juez L. On the impoliteness of some politeness strategies: a study and comparison of some pragmatic markers of impoliteness in British English and American English,

Воронежский государственный университет

Быстрых А. В., кандидат филологических наук, доиент кафедры английской филологии

E-mail: andy0210@yandex.ru

Высочкая Е. И., бакалавр кафедры английской филологии

E-mail: Ekaterina-vys@mail.ru

Поступила в редакциию 4 июля 2020 г.

Принята к публикаичи 25 сентября 2020 г.

\section{Для цитирования:}

Быстрых А. В., Высоикая Е. И. Оксюморон по форме и содержанию: дискурсивные механизмы пассивной агрессии // Вестник Воронежского государственного университета. Серия: Лингвистика и межкультурная коммуникация. 2020. № 4. C. 28-36. DOI: https://doi. org/10.17308/lic.2020.4/3077
Peninsular Spanish and Argentine Spanish. In: Studies in Intercultural, Cognitive and Social Pragmatics. Cambridge Scholar Publishing, 2007. Pp. 37-56.

Voronezh State University

Bystrykh A. V., Candidate of Philology, Associate Professor of the English Philology Department

E-mail: andy0210@yandex.ru

Vysotskaya E. I., Student of the English Philology Department

E-mail: Ekaterina-vys@mail.ru

Received: 4 July 2020

Accepted: 25 September 2020

\section{For citation:}

Bystrykh A. V., Vysotskaya E. I. Formal and conceptual oxymoron: discursive mechanisms of passive-aggressive behavior. Proceedings of Voronezh State University. Series: Linguistics and Intercultural Communication. 2020. No. 4. Pp. 28-36. DOI: https://doi.org/10.17308/lic.2020.4/3077 